\title{
American Medical Association Journal of Ethics
}

May 2015, Volume 17, Number 5: 465-468

MEDICAL NARRATIVE

\section{An Intergenerational Conversation about Frustrations, Lessons, and Hope in Physician Activism}

Shira Heisler, MD, and Gordon D. Schiff, MD

SH: There is a common narrative among interns and residents. We work crazy hours. We often feel like we're in over our heads and don't know what we're doing. And yet, somehow, we are expected to be taking good care of very sick patients, among the sickest in our cities. While being a first-year intern is well understood to be overwhelming, one of the most significant challenges is rarely discussed and confronted: that our patients, especially in distressed environments, have urgent nonmedical problems that stem from systemic injustices.

Patching patients up in order to "discharge them" (the omnipresent priority of a resident), sending them out to the same environments and situations that led to their admission, often seems even crazier than the hours we are working. Sometimes, no matter how diagnostically astute or compassionate we try to be, it seems that inadequate housing, poverty, substance misuse, and other socioeconomic forces continue to overwhelm our best efforts. For instance, how can we discharge an uninsured patient with end-stage liver disease secondary to hepatitis $C$ into homelessness when he has ascites so severe that he will need repeated therapeutic paracentesis with sterile dressing changes on a regular basis? How do we manage the care of a transgender woman with AIDS who is in and out of the hospital with opportunistic infections requiring a long course of IV antivirals? We can't keep her in the hospital for the six-week duration of treatment because she is not "acutely" ill enough to meet the criteria for admission. And the one rehabilitation facility that accepts patients with a history of recent drug use makes her feel so alienated and stigmatized about her gender identity that homelessness becomes her most reasonable option.

So, after long hours on the floors, writing endless notes, and talking to social workers until 9 p.m. about discharge planning, I'm left with perpetual questions. How can I help my patients while simultaneously working to create a more equal, just, and truly caring world?

After months of feeling this sense of hopelessness and helplessness, I was fortunate to reach out to Gordon Schiff. He has been a primary care physician and an activist for nearly 40 years, somehow maintaining both his idealism and love for medicine. I was inspired by an essay he had recently published in JAMA about crossing boundaries to care 
more fully for patients [1], and I was able to connect with him by phone. During the next hour, Dr. Schiff walked me through some ideas and strategies for surviving my internship year and the years to follow and for most effectively helping my patients.

GS: After first setting some overall priorities for managing feelings of hopelessness as physicians, we can then look at specific approaches to helping patients and ourselves. I would offer the following ideas.

\section{Setting Priorities}

1. Focus on relationships: the source of joy, meaning, and efficacy in our work. Engaging the twin problems of our patients' day-to-day medical needs and all-encompassing social and economic issues can feel overwhelming. But building meaningful, caring relationships with our patients and advocating for their needs is a gift that nourishes our ability to feel that our efforts matter and are making a difference.

2. Take advocacy seriously. Advocacy and activism are often disparaged as "not real medicine." On the contrary, engagement enhances our integrity, empathy, compassion and skills that are crucial for effective professionals-teamwork, transparency, listening to patients and placing their needs first, discerning what is best given a patient's context, and understanding social determinants of health .

3. Respect patients' amazing resilience, resourcefulness, and accomplishments. Patients' ability to survive clinical and environmental challenges never ceases to amaze me. Many overcome adversity with dignity, humor, and calm.

\section{How to Help Patients}

4. Remember that small bits of help can make an enormous difference. For our neediest patients, what seems to us like a drop in the bucket can have catalytic effects. A call to a housing agency or spouse or a letter to an employer or parole officer can be life changing and often doesn't require much work on our part.

5. Leverage your relationship to help patients. Medications or surgery aren't all we have to give patients. Working with patients in need continuously over time as their clinician, cheerleader, trusted friend, nudger (to encourage them to stop smoking, change to healthier lifestyles) produces results. And, if treated with trust and respect, patients respond in myriad positive ways, such as adhering to our recommendations, admitting when they've gone astray, and appreciating our efforts.

6. Sympathetically engage substance abuse issues, homelessness, and incarceration. The war on drugs has been a tragic (expensive, lethal) failure. Patients have been ill served by stigma, incarceration, and a lack of adequate treatment programs and effective approaches. Reach out to marginalized patients and advocate for needed help and programs we know work.

\section{How to Help Yourself}

7. Seek out hidden or dispersed sources of support. You are not alone in both caring about these issues and in feeling frustrated and isolated in your efforts to ameliorate 
them. Look for local kindred souls, including sympathetic attending physicians, fellow residents, social workers, nurses, or even clinic administrators. They are out there and they need you as a source of fresh energy and ideas, just as you need them. Get together inside and outside the hospital to discuss patients and issues.

8. Pace yourself; you are in this for the long haul. Actions that will result in lasting change don't happen overnight or when you most expect them. You will have to pick and choose your battles; you will be making compromises every day. But keep your "eye on the prize" of the larger goals and don't forget that when you fight injustice you are on the right side of history.

9. Work collectively with others in the community for change. Acting alone can have limitations, and people organizing together can be powerful. Taking risks, testing strategies, and learning from mistakes together can lead to meaningful change.

10. Leverage other initiatives, movements, and imperatives for change. Align your efforts with residency and hospital accreditation requirements to teach and practice system-based improvements and conduct performance improvement projects. Join national initiatives to organize for a better, fairer health care system (such as Physicians for a National Health Program) or for more humanism in medicine (like the Gold Foundation).

SH: As our conversation progressed, I more deeply understood why we call pushing for transformative change a struggle. It's because there are no simple or perfect solutions, and the process can be painful. The growing pains I am feeling are a result of the steep learning curve of a resident paired with the complicated reality of working in a place often full of hopelessness and pain. But as with all growing pains, this is where change and transformation take place.

Furthermore, answers to our questions are always raising new questions, and even after nearly four decades of work as a physician, Dr. Schiff is still struggling with these same concerns, dilemmas, and problems that I am. So how do we do it without getting burnt out and forgetting why we chose this profession in the first place? And how can we make the systems we work in more humane and just? Dr. Schiff's answer is that, first and foremost, we must never lose sight of the power of our smallest actions, because you don't know which of the seeds you are planting will bear fruit. I think my answer today won't necessarily be my answer tomorrow. But, today, it is remembering that this a process.

My patients - who tell me painful stories about living on the streets in freezing temperatures, who describe what it is to go through detox countless times, who talk about the ongoing trauma of living in prison for over 20 years - are the people who can teach us what resilience and strength look like. It is this strength and tenacity that reminds me, and all of us, of the power and perseverance of human beings. If we see what one individual can overcome, oftentimes with little or no support structure, imagine 
what a community of physicians, social workers, nurses, and particularly patients who share similar values and goals can do together. Imagine a world where we can help each other process the painful stories we hear and begin to think of new, creative ways of healing.

\section{References}

1. Schiff GD. A piece of my mind. Crossing boundaries--violation or obligation? JAMA. 2013;310(12):1233-1234.

Shira Heisler, MD, is an internal medicine and pediatrics resident at the Detroit Medical Center and Wayne State University in Detroit.

Gordon D. Schiff, MD, is a primary care physician who works as a safety and quality improvement researcher at Harvard Medical School's Center for Primary Care and Brigham and Women's Center for Patient Safety Research and Practice in Boston. He is a longtime activist and former advocate at Chicago's John H. Stroger, Jr. Hospital of Cook County.

Related in the AMA Journal of Ethics

Doctoring for the Homeless: Caring for the Most Vulnerable among Us by Building Trust, May 2015

A Call to Service: Social Justice Is a Public Health Issue, September 2014

Medical-Legal Partnerships, August 2011

Advocacy by Physicians for Patients and for Social Change, September 2014

Human Rights and Advocacy: An Integral Part of Medical Education and Practice, January 2004

Physicians' Social Responsibility, September 2014

The AMA Code of Medical Ethics' Opinion on Physician Advocacy, September 2014

The viewpoints expressed in this article are those of the author(s) and do not necessarily reflect the views and policies of the AMA.

Copyright 2015 American Medical Association. All rights reserved. ISSN 2376-6980 